\title{
DYNAMIC BEHAVIOR OF THE FULL-CAR MODEL IN THE J-TURN MANEUVER BY CONSIDERING THE ENGINE GYROSCOPIC EFFECTS
}

\author{
Ali Shahabi, Amir Hossein Kazemian*, Said Farahat, Faramarz Sarhaddi \\ Department of Mechanical Engineering, University of Sistan and Baluchestan, Zahedan, Iran \\ *E-mail of corresponding author: kazemian@eng.usb.ac.ir
}

\begin{abstract}
Resume
This study presents a new dynamic modeling of a vehicle by considering the engine dynamics. By selecting the vehicle coordinate system as the reference frame, all the force-torque equations of the sprung mass and unsprung masses are derived in this coordinate system by using the Newton's equations of motion. Unlike the previous researches, in this work the sprung mass of the vehicle is not considered as a rigid body. The dynamics of the sprung mass components, such as gyroscopic effects of the engine crankshaft, is considered. In order to study the vehicle's dynamic behavior, in the J-turn maneuver, the governing equations of the full-car model are evaluated and validated by the numerical simulation method and ADAMS/ Car software. Based on the results, the maximum roll angle and roll rate of a vehicle reach about 8 degrees and 40 degrees per second, respectively.
\end{abstract}

Available online: https://doi.org/10.26552/com.C.2021.3.B237-B249

\section{Article info}

Received 19 November 2020

Accepted 13 January 2021

Online 7 June 2021

\section{Keywords:}

J-turn maneuver, full-car model, engine crankshaft, dynamic behavior

ISSN $1335-4205$ (print version) ISSN 2585-7878 (online version)

\section{Introduction}

Safety assessment is one of the most important issues in the automotive industry. The safety of vehicles can be examined from two perspectives: the pre-crash safety and post-crash safety. Stability analysis is an important factor in the pre-crash safety and vehicle instability plays a major role in fatal crashes. Understanding the dynamic behavior of a vehicle in standard maneuvers can be effective in assessing its stability.

A set of experimental examinations was performed to evaluate the actual dynamic behavior of a vehicle in various standard maneuvers [1], from which the phase IV rollover tests of the National Highway Traffic Safety Administration (NHTSA) [2] can be pointed out. Cooperrider et al. [3] performed experiments to investigate tripped rollover, the results of which included five types of the curb-tripped rollover tests. In their researches, acceptable information was obtained through the minimum required speed for the rollover occurring, as well as the characteristics of the rollover phenomenon at different speeds. Labuda et al. [4] studied the simulation of wheeled vehicle dynamic regimes in laboratory conditions by considering the congruent courses of driving speeds. Sindha et al. [5] developed an experimental prototype along with its simulation to study the steer system on the vehicle stability improvement. Zhang et al. investigated the vehicle maneuverability and its lateral stability by experimental validations, [6]. Phanomchoeng and Rajamani [7] developed a new rollover index that can detect both tripped and untripped rollovers by experimental and simulation examinations. The purpose of computer simulations is to reveal the effect of systems and components on the dynamic behavior of a vehicle as much as possible. By using the computer simulations, this purpose can be reached much earlier in the targeting and initial design stages of a vehicle than for the actual prototype. Chen et al. [8] simulated the rollover dynamics, such as rollover speed thresholds of a vehicle in roundabouts. Loktev et al. [9] determined the geometric, kinematic and dynamic characteristics of a vehicle and its state parameters on the road by computer vision algorithms. Phalke and Mitra [10] simulated a quarter-car model to investigate the effect of damping coefficient, stiffness, sprung mass and velocity on ride comfort and road holding. Saga et al. [11] investigated possibilities of a fuzzy technique in a vehicle dynamic analysis by computer simulations. Kazemian et al. [12-13] presented the rollover index and new dynamics of suspension system in order to study the vehicle's dynamic behavior by computer simulations. Rajamani [14] and Gillespie [15] studied the vehicle dynamics and its subsystems such as tire in order to study on the vehicle's dynamic behavior, such as roll and yaw dynamics, by considering the dynamics' basics [16]. Pacejka [17-19] examined the tire characteristics, such 
as its longitudinal and lateral forces and obtained the data, by mathematical expressions based on a formula. In vehicles, knowing the dynamic behavior of the engine elements, such as crankshaft, can be useful for obtaining the dynamic behavior of the vehicle [2021]. The effect of static misalignment on the dynamic behavior of a main crankshaft bearing is examined by Lahmar et al. [22]. Ahmadabadi [23] proposed an application of lightweight vibration control strategy known as nonlinear energy sink (NES) to mitigate the undesired vibrations in engine crankshaft systems. Huang et al. [24] proposed a method for dynamic balance measurement and imbalance compensation of crankshaft assemblies. Moreover, basic researches of dynamic modeling have been reported in [25-28]

This study, by presenting a 15-DOF model of the vehicle dynamics, considers reducing the complexity of the model to the extent that it would be acceptable for the dynamic behavior of the vehicle studying and modeling the necessary subsystems, such as tire and engine, with sufficient accuracy. The tire is modeled with the Pacejka 89 model, which calculates the tire forces using the longitudinal and lateral slips. The moments due to the gyroscopic effect of engine rotation are taken into account in the equations and the final equations of motion of the vehicle were derived. The dynamic behavior of the $15-\mathrm{DOF}$ presented model is validated by the ADAMS/Car software. Dynamic behavior and stability of a vehicle in the J-turn maneuver is simulated by the Newmark numerical method under the supervision of the NHTSA, [25].

\section{Modeling and equations}

In this research, the vehicle is considered as a set of lumped masses including the sprung mass and four unsprung masses as a set of wheels and tires. The unsprung masses are connected to the sprung mass by the spring and a damper. Each tire is assumed equivalent to a spring and a damper, parallel in the vertical direction. The number of degrees of freedom that are considered for the vehicle model is 15 , out of which 6 DOFs are related to translation and rotation of the sprung mass. The next 4 DOFs are for vertical movement of the unsprung masses, which indicate the vertical movement of the suspension systems, while the following 4 DOFs are related to rotation of the wheels around their axes and 1 DOF is considered for steerability of the front wheels. For this set of masses, separate coordinate systems, such as fixed inertial coordinate system (O), sprung mass coordinate system (S), roll axis coordinate system (vehicle coordinates $(\mathrm{V})$ ) and wheel coordinate system (US), are considered. The direction of the coordinate systems, as shown in Figure 1, is in accordance with the SAE (Society of Automotive Engineers) standard [15]. In Figure 1 the sprung mass coordinate system is located at its center of gravity (CGS). The coordinate system located on the roll axis, which is the most important coordinate system and all variables are expressed in that system, is located at a point on the roll axis and below the center of gravity of the vehicle mass (VCG). It is also assumed that this coordinate system rotates only around the $\mathrm{Z}$ axis. To obtain the equations of wheels motion in the vertical direction and around their rotation axis for each wheel, a coordinate system is used at the center of rotation. According to coordinate systems and using the Newton's equations of motion, all equations of motion for the sprung and unsprung masses are obtained in the vehicle coordinate system. Therefore, for the sprung mass, the following Equations can be written:

$$
\begin{aligned}
& \omega_{V}^{V}=\left\{\begin{array}{lll}
0 & 0 & \dot{\varphi}
\end{array}\right\}^{T}, V_{V}^{V}=\left\{\begin{array}{lll}
V_{x} & V_{y} & 0
\end{array}\right\}^{T},, \\
& \rho_{C G S}^{V}=\left\{\begin{array}{lll}
l_{s} & 0 & h_{s}
\end{array}\right\}^{T}, \\
& V_{C G S}^{V}=\left\{\begin{array}{llll}
V_{x} & V_{y} & V_{z}
\end{array}\right\}^{T}=\left\{\begin{array}{lll}
V_{x} & V_{y} & \dot{Z}_{C G S}
\end{array}\right\}, \\
& \omega_{S}^{V}=\{\dot{\theta} \cos \phi \dot{\phi} \cos \theta \dot{\varphi}+\dot{\phi} \sin \theta+\dot{\theta} \sin \phi\}^{T} \\
& \stackrel{\sin \phi=\phi=0, \cos \phi=1}{\longrightarrow} \omega_{S}^{V}=\{\dot{\theta} \dot{\phi} \cos \theta \dot{\varphi}+\phi \sin \theta\}^{T} \text {, } \\
& V_{S}^{V}=V_{C G S}^{V}+\omega_{S}^{V} \times \rho_{C G S}^{V} \rightarrow V_{S}^{V}= \\
& \left\{\begin{array}{c}
V_{x}+h_{s} \dot{\phi} \cos \theta \\
V_{y}-h_{s} \dot{\theta}+l_{s}(\dot{\varphi}+\dot{\phi} \sin \theta) \\
\dot{Z}_{C G S}-l_{S} \dot{\phi} \cos \theta
\end{array}\right\} \text {. }
\end{aligned}
$$

Similarly, for the unsprung masses, next Equations are obtained:

$$
\begin{aligned}
& \omega_{u s f R}^{V}=\left\{\omega_{w} \sin \delta_{f R} \omega_{w} \cos \delta_{f R} \dot{\varphi}\right\}^{T}, \\
& \omega_{u s f L}^{V}=\left\{\omega_{W} \sin \delta_{f L} \omega_{W} \cos \delta_{f L} \dot{\varphi}\right\}^{T} \\
& \omega_{u s r L}^{V}=\left\{\begin{array}{lll}
0 & \omega_{w} \dot{\varphi}
\end{array}\right\}^{T}, \omega_{u s r R}^{V}=\left\{\begin{array}{lll}
0 & \omega_{w} \dot{\varphi}
\end{array}\right\}^{T}, \\
& V_{C G u s i j}^{V}=\left\{\begin{array}{lll}
V_{x} & V_{y} & \dot{Z}_{u s i j}
\end{array}\right\}^{T} \\
& \rho_{u s f R}^{V}=\left\{l_{f} t / 2 Z_{u s f R}\right\}^{T}, \rho_{u s f L}^{V}=\left\{l_{f}-t / 2 Z_{u s f L}\right\}^{T}, \\
& \rho_{u s r L}^{V}=\left\{l_{r}-t / 2 Z_{u s r L}\right\}^{T}, \rho_{u s r R}^{V}=\left\{l_{r} t / 2 Z_{u s r R}\right\}^{T}, \\
& V_{C G u s i j}^{V}=V_{C G u s i j}^{V}+\omega_{u s i j}^{V} \times \rho_{C G u s i j}^{V} \rightarrow V_{u s f R}^{V}= \\
& \left\{\begin{array}{c}
V_{x}+Z_{u s f R} \omega_{w} \cos \delta_{f R}-\left(\frac{t}{2}\right) \dot{\varphi} \\
V_{y}-Z_{u s f R} \omega_{w} \sin \delta_{f R}+l_{f} \dot{\varphi} \\
\dot{Z}_{u s f R}+\omega_{w}\left(\frac{t}{2} \sin \delta_{f R}-l_{f} \cos \delta_{f R}\right)
\end{array}\right\}, \\
& V_{u s f L}^{V}=\left\{\begin{array}{c}
V_{x}+Z_{u s f L} \omega_{w} \cos \delta_{f L}-\left(\frac{t}{2}\right) \dot{\varphi} \\
V_{y}-Z_{u s f L} \omega_{w} \sin \delta_{f L}+l_{f} \dot{\varphi} \\
\dot{Z}_{u s f L}+\omega_{w}\left(\frac{t}{2} \sin \delta_{f L}-l_{f} \cos \delta_{f L}\right)
\end{array}\right\}, \\
& V_{u s r L}^{V}=\left\{\begin{array}{c}
V_{x}+Z_{u s r L} \omega_{w}+\left(\frac{t}{2}\right) \dot{\varphi} \\
V_{y}+l_{r} \dot{\varphi} \\
Z_{u s r L}-\omega_{w} l_{r}
\end{array}\right\}, \\
& V_{u s r R}^{V}=\left\{\begin{array}{c}
V_{x}+Z_{u s r R} \omega_{w}+\left(\frac{t}{2}\right) \dot{\varphi} \\
V_{y}+l_{r} \dot{\varphi} \\
Z_{u s r R}-\omega_{w} l_{r}
\end{array}\right\} .
\end{aligned}
$$

By placing velocities of Equations (1)-(3) in the Newton's linear momentum equation of the sprung mass, the force vector of the sprung mass in the vehicle coordinate system is obtained: 


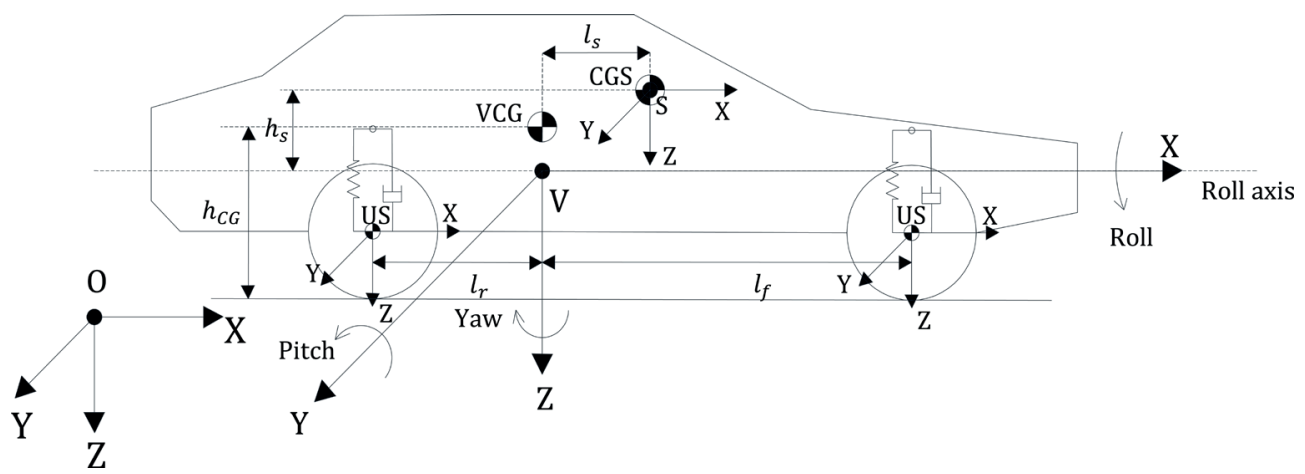

Figure 1 Direction of the vehicle coordinate system according to the SAE standard

$F_{S}^{V}=m_{S}\left[\frac{d}{d t} V_{S}^{V}+\omega_{V}^{V} \times V_{S}^{V}\right] \rightarrow F_{S}^{V}=$

$m_{s}\left\{\begin{array}{c}\dot{V}_{x}+h_{s}\left(\begin{array}{c}\ddot{\phi} \cos \theta- \\ -\dot{\phi} \dot{\theta} \sin \theta\end{array}\right)-\dot{\varphi}\left(\begin{array}{c}V_{y}-h_{s} \dot{\theta}+ \\ l_{s}(\dot{\varphi}+\phi \sin \theta)\end{array}\right) \\ \dot{V}_{y}-h_{s} \ddot{\theta}+ \\ +l_{s}\left(\begin{array}{c}\ddot{\varphi}+\ddot{\phi} \sin \theta+ \\ +\dot{\varphi} \dot{\theta} \cos \theta \\ Z_{C G S}-l_{s}(\ddot{\phi} \cos \theta+\dot{\phi} \dot{\theta} \sin \theta)\end{array}\right\} . \dot{\varphi}\left(V_{x}+h_{s} \dot{\phi} \cos \theta\right)\end{array}\right\}$

Similarly, for the unsprung masses the following Equations are obtained:

$$
\begin{aligned}
& F_{u s i j}^{V}=m_{u s i j}\left[\frac{d}{d t} V_{u s i j}^{V}+\omega_{V}^{V} \times V_{u s i j}^{V}\right],
\end{aligned}
$$

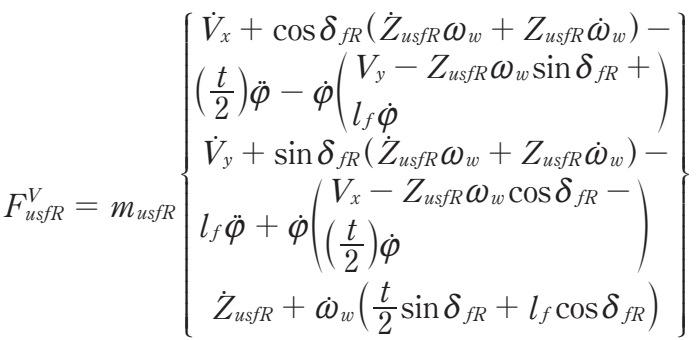

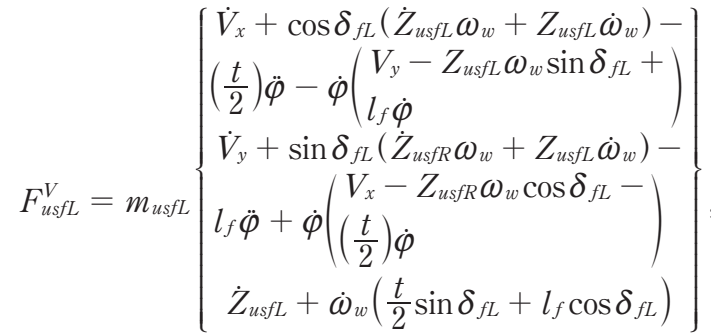

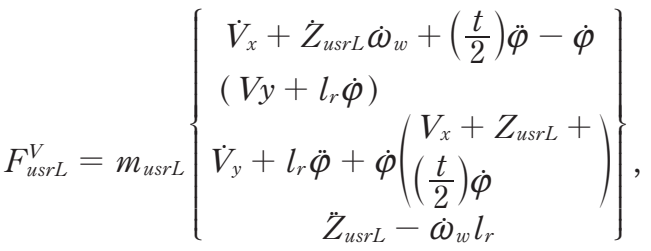

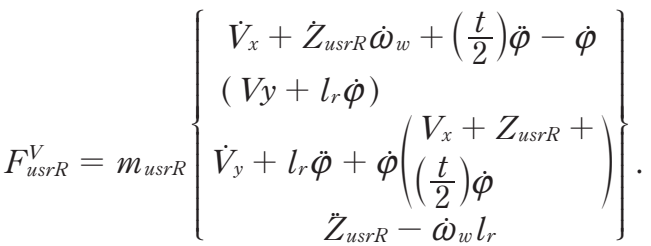

According to Equation (13), the total forces acting on the vehicle include the forces acting on all the sprung and unsprung masses:

$$
\begin{aligned}
& F_{V}^{V}=F_{S}^{V}+F_{u s i j}^{V}= \\
& m \dot{V}_{x}-m \varphi V_{y}+m_{s}\left[h_{s}(\ddot{\phi} \cos \theta-\right. \\
& \left.\dot{\phi} \dot{\theta} \sin \theta+\dot{\varphi} \dot{\theta})-l_{s}\left(\dot{\phi} \dot{\varphi} \sin \theta+\dot{\varphi}^{2}\right)\right]+m_{u s f} \\
& {\left[\begin{array}{c}
\cos \delta_{f}\left(\begin{array}{l}
\omega_{w}\left(\dot{Z}_{u s f R}+\dot{Z}_{u s f L}\right) \\
+\omega_{w}\left(Z_{u s f R}+Z_{u s f L}\right)
\end{array}\right)+\dot{\varphi} \omega_{w} \sin \delta_{f} \\
\left(Z_{u s f R}+Z_{u s f L}\right)-2 \dot{\varphi}^{2} l_{f}
\end{array}\right]+} \\
& m_{u s r}\left[\begin{array}{l}
\omega_{w}\left(\dot{Z}_{u s R}+\dot{Z}_{u s L}\right)+\dot{\omega}_{w}\left(Z_{u s R}+Z_{u s L}\right)- \\
2 \dot{\phi}^{2} l_{r}
\end{array}\right]+ \\
& \left.m \dot{V}_{y}+m \dot{\varphi} V_{x}-m_{s}\left[\begin{array}{l}
h_{s}(\ddot{\theta}-\dot{\phi} \dot{\varphi} \cos \theta)+l_{s} \\
(\ddot{\varphi}-\ddot{\phi} \sin \theta-\dot{\phi} \dot{\theta} \cos \theta)
\end{array}\right]+\right\} \text {. } \\
& m_{u s f}\left[\begin{array}{c}
-\sin \delta_{f}\left(\begin{array}{c}
\omega_{w}\left(\dot{Z}_{u s f R}+Z_{u s f L}\right) \\
+\omega_{w}\left(Z_{u s f R}+Z_{u s f L}\right)
\end{array}\right)+ \\
2 \ddot{\varphi} l_{f}+\dot{\varphi} \omega_{w} \cos \delta_{f}\left(Z_{u s f R}+Z_{u s f L}\right)
\end{array}\right]+m_{u s r} \\
& \left.\left[\dot{\varphi} \omega_{w}\left(Z_{u s r R}+Z_{u s r L}\right)+2 \ddot{\varphi} l_{r}\right] m_{s}\left[\begin{array}{l}
\ddot{Z}_{C G S}-l_{s} \\
\ddot{\phi} \cos \theta- \\
\dot{\phi} \dot{\theta} \sin \theta
\end{array}\right)\right]+ \\
& m_{u s f}\left[\ddot{Z}_{u s f L}+\ddot{Z}_{u s f R}-2 \dot{\omega}_{w} l_{f} \cos \delta_{f}\right]+m_{u s r} \\
& {\left[\ddot{Z}_{u s r L}+\ddot{Z}_{u s r R}-2 \dot{\omega}_{w} l_{r}\right]}
\end{aligned}
$$

where $m=m_{s}+2 m_{u s f}+2 m_{u s r}$ is the total mass of a vehicle. According to the Newton's angular momentum equation, the resultant of the torques, acting on the body, is equal to change of the body's angular momentum. If one writes this relation for the center of the vehicle's coordinate system, the distance of which to the center of the sprung mass coordinate system remains constant, Equation is obtained:

$$
M_{S}^{V}=R_{S}^{V} M_{S}^{S}=R_{S}^{V} \frac{d}{d t}\left(I_{S}^{S} \omega_{S}^{S}\right)
$$

where $R_{S}^{V}$ is the matrix of coordinate transformation from the sprung mass coordinates to the vehicle coordinates (see Appendix 1). Assuming that values of inertia moments remain constant, with small rotation of the roll and pitch of a vehicle, on obtains:

$M_{S}^{V}=I_{S}^{V} \dot{\omega}_{S}^{V}+\omega_{S}^{V} \times\left(I_{S}^{V} \omega_{S}^{V}\right)$

where: 


$$
\begin{aligned}
& \dot{\omega}_{S}^{V}=\frac{d}{d t} \omega_{S}^{V}+\omega_{V}^{V} \times \omega_{S}^{V}= \\
& \left\{\begin{array}{c}
\ddot{\theta}-\dot{\varphi} \dot{\phi} \cos \theta \\
\ddot{\phi} \cos \theta-\dot{\phi} \dot{\theta} \sin \theta+\dot{\theta} \dot{\varphi} \\
\ddot{\varphi}+\ddot{\phi} \sin \theta+\dot{\phi} \dot{\theta} \cos \theta
\end{array}\right\} .
\end{aligned}
$$

Since the xy plane is a symmetry plane of the vehicle with a good approximation, so $I_{x y}=I_{y z}=0$ and with ignoring the value of $I_{x z}$, the matrix of the sprung mass inertia moments is presented by:

$$
I_{S}^{V}=\left[\begin{array}{ccc}
I_{x x} & I_{x y} & I_{x z} \\
I_{y x} & I_{y y} & I_{y z} \\
I_{z x} & I_{z y} & I_{z z}
\end{array}\right] \rightarrow I_{S}^{V}=\left[\begin{array}{ccc}
I_{x x} & 0 & 0 \\
0 & I_{y y} & 0 \\
0 & 0 & I_{z z}
\end{array}\right]
$$

By placing $\omega_{S}^{V}, \dot{\omega}_{S}^{V}$ and $I_{S}^{V}$, respectively, from Equations (2), (16) and (17) in Equation (15), one obtains:

$$
M_{S}^{V}=\left\{\begin{array}{l}
I_{x x}(\ddot{\theta}-\dot{\varphi} \dot{\phi} \cos \theta)+\left(I_{z z}-I_{y y}\right) \times \\
\left(\dot{\varphi} \dot{\phi} \cos \theta+\dot{\phi}^{2} \theta \cos \theta\right) \\
I_{y y}(\ddot{\phi} \cos \theta-\dot{\phi} \dot{\theta} \sin \theta+\dot{\theta} \dot{\varphi})+ \\
\left(I_{x x}-I_{z z}\right)(\dot{\phi} \dot{\theta} \sin \theta+\dot{\theta} \dot{\varphi}) \\
I_{z z}(\ddot{\varphi}+\ddot{\phi} \sin \theta+\dot{\phi} \dot{\theta} \cos \theta)+ \\
\left(I_{y y}-I_{x x}\right) \dot{\phi} \dot{\theta} \cos \theta
\end{array}\right\} .
$$

To derive the equation of the unsprung mass angular momentum, similar to e equation of the sprung mass angular momentum (15), Equations (19)-(21) are obtained as follows:

$$
\begin{aligned}
& M_{u s i j}^{V}=I_{u s i j}^{V} \dot{\omega}_{u s i j}^{V}+\omega_{u s i j}^{V} \times\left(I_{u s i j}^{V} \omega_{u s i j}^{V}\right), \\
& \dot{\omega}_{u s i j}^{V}=\frac{d}{d t} \omega_{u s i j}^{V}+\omega_{V}^{V} \times \omega_{u s i j}^{V} \rightarrow \dot{\omega}_{u s f R}^{V}= \\
& \left\{\begin{array}{c}
\dot{\omega}_{w} \sin \delta_{f R}-\dot{\varphi} \omega_{w} \cos \delta_{f R} \\
\left.\dot{\omega}_{w} \cos \delta_{f R}+\dot{\varphi} \omega_{w} \sin \delta_{f R}\right\} \\
\ddot{\varphi}
\end{array}\right\}, \\
& \dot{\omega}_{u s f L}^{V}=\left\{\begin{array}{c}
\dot{\omega}_{w} \sin \delta_{f L}-\dot{\varphi} \omega_{w} \cos \delta_{f L} \\
\dot{\omega}_{w} \cos \delta_{f L}+\dot{\varphi} \omega_{w} \sin \delta_{f L} \\
\dot{\varphi}
\end{array}\right\}, \\
& \dot{\omega}_{u s r L}^{V}=\left\{\begin{array}{c}
-\dot{\varphi} \omega_{w} \\
\dot{\omega}_{w} \\
\ddot{\varphi}
\end{array}\right\}, \dot{\omega}_{u s r R}^{V}=\left\{\begin{array}{c}
-\dot{\varphi} \omega_{w} \\
\dot{\omega}_{w} \\
\ddot{\varphi}
\end{array}\right\}, \\
& M_{u s f R}^{V}=\left\{\begin{array}{c}
I_{x x u s f}\left(\dot{\omega}_{w} \sin \delta_{f R}-\dot{\varphi} \omega_{w} \cos \delta_{f R}\right)+ \\
\left(I_{z z u s f}-I_{y y u s f}\right) \dot{\varphi} \omega_{w} \cos \delta_{f R} \\
I_{y y u s f}\left(\dot{\omega}_{w} \cos \delta_{f R}-\dot{\varphi} \omega_{w} \sin \delta_{f R}\right)+ \\
\left(I_{x x u s f}-I_{z z u s f}\right) \dot{\varphi} \omega_{w} \sin \delta_{f R} \\
I_{z z u s f} \ddot{\varphi}+\left(I_{y y u s f}-I_{x x u s f}\right) \times \\
\omega_{w}^{2} \sin \delta_{f R} \cos \delta_{f R}
\end{array}\right\}, \\
& M_{u s f L}^{V}=\left\{\begin{array}{c}
I_{x x u s f}\left(\dot{\omega}_{w} \sin \delta_{f L}-\dot{\varphi} \omega_{w} \cos \delta_{f L}\right)+ \\
\left(I_{z z u s f}-I_{y y u s f}\right) \dot{\varphi} \omega_{w} \cos \delta_{f L} \\
I_{y y u s f}\left(\dot{\omega}_{w} \cos \delta_{f L}-\dot{\varphi} \omega_{w} \sin \delta_{f L}\right)+ \\
\left(I_{x x u s f}-I_{z z u s f}\right) \dot{\varphi} \omega_{w} \sin \delta_{f L} \\
I_{z z u s f} \ddot{\varphi}+\left(I_{y y u s f}-I_{x x u s f}\right) \times \\
\omega_{w}^{2} \sin \delta_{f L} \cos \delta_{f L}
\end{array}\right\},
\end{aligned}
$$

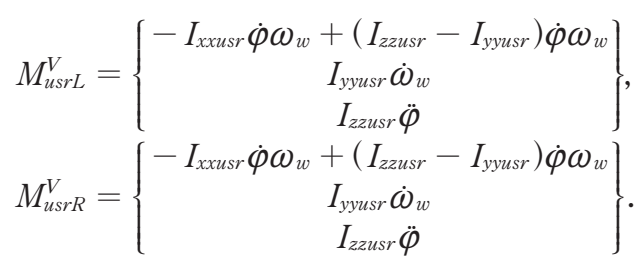

Considering that the coordinate center of a vehicle is a point that differs from the center of mass of the sprung and unsprung masses, the total torque applied to the vehicle can be calculated as [16]:

$\left(H_{Q}\right)_{\text {rel }}=\left(H_{G}\right)_{\text {rel }}+\bar{\rho} \times m V_{\text {rel }}$.

Equation (22) shows the angular torque around the desired point $\mathrm{Q}$. According to the toques principle in which the sum of the torques of all the external forces of a system around the point $\mathrm{Q}$ must be equal to resultant torque around $\mathrm{Q}$ and the following Equation is obtained:

$\sum M_{Q}=\sum M_{G}+\bar{\rho} \times \sum F$.

By placing the vector of forces and torques in Equation (23) for the proposed vehicle model, one obtains:

$M_{V}^{V}=M_{S}^{V}+M_{u s i j}^{V}+\rho_{C G S}^{V} \times F_{S}^{V}+\rho_{u s i j}^{V} \times F_{u s i j}^{V}$.

By entering the force-torque equations (Equations (7), (9)-(12), (18) and (21)) in Equation (24), the torque components of the vehicle are obtained:

$$
\begin{aligned}
& M_{V X}^{V}=I_{x x}(\ddot{\theta}-\dot{\varphi} \dot{\phi} \cos \theta)+\left(I_{z z}-I_{y y}\right) \times \\
& \left(\dot{\varphi} \dot{\phi} \cos \theta+\dot{\phi}^{2} \sin \theta \cos \theta\right)+2 I_{\text {xxusf }} \times \\
& \left(\dot{\omega}_{w} \sin \delta_{f}-\dot{\varphi} \omega_{w} \cos \delta_{f}\right)+2\left(I_{z z u s f}-I_{y y u s f}\right) \times \\
& \dot{\varphi} \omega_{w} \cos \delta_{f}-2 I_{x x u s r} \dot{\varphi} \omega_{w}+2\left(I_{z z u s r}-I_{y y u s r}\right) \dot{\varphi} \omega_{w}- \\
& m_{s} h_{s}\left[\begin{array}{l}
\dot{V}_{y}-h_{s} \ddot{\theta}+l_{s}(\ddot{\varphi}+\ddot{\phi} \sin \theta+\dot{\phi} \dot{\theta} \cos \theta) \\
+\dot{\varphi}\left(V_{x}+h_{s} \dot{\phi} \cos \theta\right)
\end{array}\right]+ \\
& \frac{t}{2}\left[\begin{array}{l}
m_{u s f}\left(\ddot{Z}_{u s f R}-\ddot{Z}_{u s f L}+\dot{\omega}_{w} t \sin \delta_{f}\right)+ \\
m_{u s f}\left(\ddot{Z}_{u s R}-\ddot{Z}_{u s r L}+\dot{\omega}_{w} t\right)
\end{array}\right]-m_{u s f} \times \\
& {\left[\begin{array}{l}
Z_{u s f R}\left(\begin{array}{l}
\dot{V}_{y}-\sin \delta_{f}\left(\dot{Z}_{u s f R} \dot{\omega}_{w}+Z_{u s f R} \dot{\omega}_{w}\right)+ \\
l_{f} \ddot{\varphi}+\dot{\varphi}\left(V_{x}+Z_{u s f R} \omega_{w} \cos \delta_{f}-\frac{t}{2} \dot{\varphi}\right)
\end{array}\right)+ \\
Z_{u s f L}\left(\begin{array}{l}
\dot{V}_{y}-\sin \delta_{f}\left(\dot{Z}_{u s f L} \omega_{w}+Z_{u s f L} \dot{\omega}_{w}\right)+ \\
l_{f} \ddot{\varphi}+\left(V_{x}+Z_{u s f L} \omega_{w} \cos \delta_{f}+\frac{t}{2} \dot{\varphi}\right)
\end{array}\right)
\end{array}\right]-}
\end{aligned}
$$

$m_{u s r} \times$

$\left[\begin{array}{c}Z_{u s f L}\left(\begin{array}{l}\dot{V}_{y}-\sin \delta_{f}\left(\dot{Z}_{u s f L} \dot{\omega}_{w}+Z_{u s f L} \dot{\omega}_{w}\right)+ \\ l_{f} \ddot{\varphi}+\dot{\varphi}\left(V_{x}+Z_{u s f L} \omega_{w} \cos \delta_{f}-\frac{t}{2} \dot{\varphi}\right)\end{array}\right)+ \\ Z_{u s f R}\left(\begin{array}{l}\dot{V}_{y}-\sin \delta_{f}\left(\dot{Z}_{u s f R} \omega_{w}+Z_{u s f R} \dot{\omega}_{w}\right)+ \\ l_{f} \ddot{\varphi}+\left(V_{x}+Z_{u s f R} \omega_{w} \cos \delta_{f}+\frac{t}{2} \dot{\varphi}\right)\end{array}\right)\end{array}\right]$

$M_{V Y}^{V}=I_{y y}(\ddot{\phi} \cos \theta-\dot{\phi} \dot{\theta} \sin \theta+\dot{\theta} \dot{\varphi})+\left(I_{x x}-I_{z z}\right)$

$(\dot{\phi} \dot{\theta} \sin \theta+\dot{\theta} \dot{\varphi})+2 I_{\text {yyusf }}\left(\dot{\omega}_{w} \cos \delta_{f}+\dot{\varphi} \omega_{w} \sin \delta_{f}\right)+$ $2\left(I_{x x u s f}-I_{z z u f}\right) \dot{\varphi} \omega_{w} \sin \delta_{f}+2 I_{y y u s r} \dot{\omega}_{w}+m_{s} h_{s}\left[\dot{V}_{x}+\right.$ $h_{s} \ddot{\phi} \cos \theta-h_{s} \dot{\phi} \dot{\theta} \sin \theta+l_{s}(\ddot{\varphi}+\ddot{\phi} \sin \theta+\dot{\phi} \dot{\theta} \sin \theta)-$ 


$$
\begin{aligned}
& \left.-\dot{\varphi}\left(V_{y}-h_{s} \dot{\theta}+l_{s}(\dot{\varphi}+\dot{\phi} \sin \theta)\right)\right]-m_{s} l_{s} \times \\
& \left(\ddot{Z}_{C G S}-l_{s} \ddot{\phi} \cos \theta+l_{s} \dot{\phi} \dot{\theta} \sin \theta\right)+m_{u s f} \times \\
& {\left[2 l_{f} \dot{\omega}_{w} \cos \delta_{f}-\ddot{Z}_{u s f R}-\ddot{Z}_{u s f L}\right]+m_{u s r} l_{r} \times} \\
& {\left[2 l_{r} \dot{\omega}_{w} \cos \delta_{f}-\ddot{Z}_{u s r R}-\ddot{Z}_{u s r L}\right]+m_{u s f} \times\left[Z_{u s f R} \times\right.} \\
& \left(\dot{V}_{x}+\cos \delta_{f}\left(\dot{Z}_{u s f R} \omega_{w}+Z_{u s f R} \dot{\omega}_{w}\right)-\frac{t}{2} \ddot{\varphi}-\right. \\
& \left.\dot{\varphi}\left(V_{y}-Z_{u s f R} \omega_{w} \sin \delta_{f}+l_{f} \dot{\varphi}\right)\right)+Z_{u s f L}\left(\dot{V}_{x}+\right. \\
& \cos \delta_{f}\left(\dot{Z}_{u s f L} \omega_{w}+Z_{u s f L} \dot{\omega}_{w}\right)-\frac{t}{2} \ddot{\varphi}-\dot{\varphi} \times \\
& \left.\left.\left(V_{y}-Z_{u s f L} \omega_{w} \sin \delta_{f}+l_{f} \dot{\varphi}\right)\right)\right]+m_{u s r}\left[Z_{u s f L} \times\right. \\
& \left(\dot{V}_{x}+\cos \delta_{f}\left(\dot{Z}_{u s f L} \omega_{w}+Z_{u s f L} \dot{\omega}_{w}\right)-\frac{t}{2} \ddot{\varphi}-\right. \\
& \left.\dot{\varphi}\left(V_{y}-Z_{u s f L} \omega_{w} \sin \delta_{f}+l_{f} \dot{\varphi}\right)\right)+Z_{u s f R}\left(\dot{V}_{x}+\right. \\
& \cos \delta_{f}\left(\dot{Z}_{u s f R} \omega_{w}+Z_{u s f R} \dot{\omega}_{w}\right)-\frac{t}{2} \ddot{\varphi}-\dot{\varphi} \times \\
& \left.\left.\left(V_{y}-Z_{u s f R} \omega_{w} \sin \delta_{f}+l_{f} \dot{\varphi}\right)\right)\right] \text {, } \\
& M_{V Z}^{V}=I_{z Z}(\ddot{\varphi}+\ddot{\phi} \sin \theta+\dot{\phi} \dot{\theta} \cos \theta)+\left(I_{y y}-I_{x x}\right) \\
& \dot{\phi} \dot{\theta} \cos \theta+2 I_{z z u s f} \ddot{\varphi}+2\left(I_{\text {yyusf }}-I_{\text {xxusf }}\right) \omega_{w}^{2} \sin \delta_{f} \times \\
& \cos \delta_{f}+2 I_{z z u s r} \ddot{\varphi}+m_{s} l_{s}\left[\dot{V}_{y}-h_{s} \ddot{\theta}+l_{s}(\ddot{\varphi}+\right. \\
& \left.\left.\ddot{\phi} \sin \theta+\dot{\phi} \dot{\theta} \cos \theta+h_{s} \dot{\phi} \dot{\varphi} \cos \theta+\dot{\varphi} \dot{V}_{x}\right)\right]+m_{u s f} \times \\
& {\left[l _ { f } \left(2 \dot{V}_{y}-\sin \delta_{f}\left(\left(\dot{Z}_{u s f R}+\dot{Z}_{u s f L}\right) \omega_{w}+\right.\right.\right.} \\
& \left.\left(Z_{u s f R}+Z_{u s f L}\right) \dot{\omega}_{w}\right)+2 l_{f} \ddot{\varphi}+\dot{\varphi}\left(2 V_{x}+\omega \cos \delta_{f} \times\right. \\
& \left.\left.\left(Z_{u s f R}+Z_{u s f L}\right)\right)\right)+\frac{t}{2}\left(\cos \delta_{f} \omega_{w}\left(\dot{Z}_{u s f R}+\dot{Z}_{u s f L}\right)+\right. \\
& \left.\dot{\omega}\left(Z_{u s f R}+Z_{u s f L}\right)\right)+t \ddot{\varphi}-\dot{\varphi} \omega_{w} \sin \delta_{f} \times \\
& \left.\left.\left(Z_{u s f R}+Z_{u s f L}\right)\right)\right]+m_{u s r}\left[l _ { r } \left(2 \dot{V}_{y}-\left(\dot{Z}_{u s r R}+\dot{Z}_{u s r L}\right) \times\right.\right. \\
& \omega_{w}+\left(Z_{u s r R}+Z_{u s r L}\right) \dot{\omega}_{w}+2 l_{r} \ddot{\varphi}+\dot{\varphi}\left(2 V_{x}+\omega_{w} \times\right. \\
& \left.\left.\left(Z_{u s r R}+Z_{u s r L}\right)\right)\right)+\frac{t}{2}\left(\omega_{w}\left(\dot{Z}_{u s r L}+\dot{Z}_{u s r R}\right)+\right. \\
& \left.\left.\dot{\omega}_{w}\left(Z_{u s r R}+Z_{u s r L}\right)+t \ddot{\varphi}-\dot{\varphi} \omega_{w}\left(Z_{u s r R}+Z_{u s r L}\right)\right)\right] .
\end{aligned}
$$

The left-hand side of Equations (13) and (25)(27), which are the main equations of motion of the vehicle, includes the forces and torques of the external forces applied to the vehicle and an example of them is shown in Figures 2 and 3. Note that by considering the directions of the coordinate systems, these forces and torques are entered into the equations of motion of the vehicle.

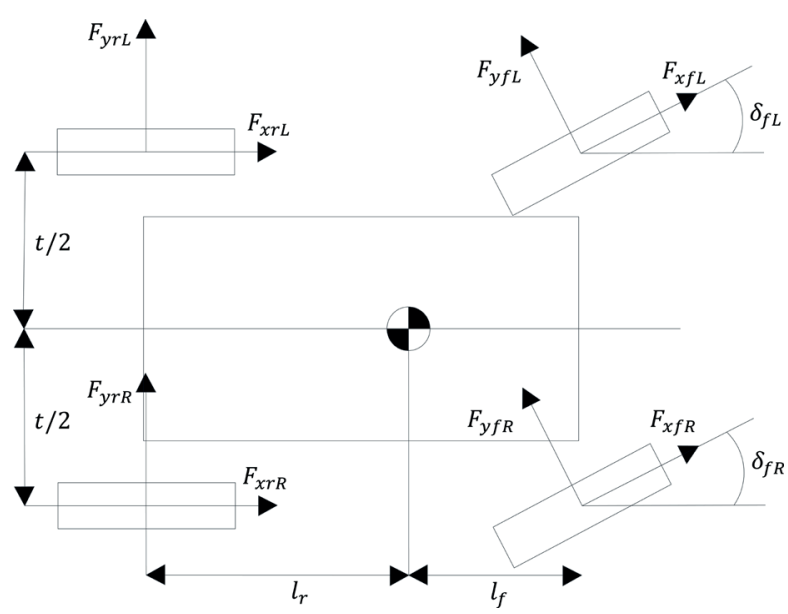

Figure 2 External forces on the xy plane of vehicle coordinate system

\subsection{Equations of external forces}

By writing the resultant of forces and torques applied to the vehicle, next two Equations are obtained:

$$
F_{V}^{V}=\left\{\begin{array}{c}
F_{x f R} \cos \delta_{f R}-F_{y f R} \sin \delta_{f R}+F_{x f L} \cos \delta_{f L}- \\
F_{y f L} \sin \delta_{f L}+F_{x r R}+F_{x r L} \\
F_{y f R} \cos \delta_{f R}+F_{x f R} \sin \delta_{f R}+F_{y f L} \cos \delta_{f L}+ \\
F_{x f L} \sin \delta_{f L}+F_{y r R}+F_{y r L} \\
m_{s} g-k_{i j}\left(Z_{n}-Z_{u s i j}\right)-c_{i j}\left(\dot{Z}_{n}-\dot{Z}_{u s i j}\right) \\
n=1,2,3,4
\end{array}\right\},
$$

where $n$ shows the unsprung masses.

$$
M_{V}^{V}=\left\{\begin{array}{l}
\frac{t}{2}\left[-k_{f R}\left(Z_{1}-Z_{u s f R}\right)-k_{r R}\left(Z_{4}-Z_{u s r R}\right)+\right. \\
k_{f L}\left(Z_{2}-Z_{u s f L}\right)+k_{r L}\left(Z_{3}-Z_{u s r L}\right)-c_{f R} \times \\
\left(Z_{1}-Z_{u s f R}\right)-c_{r R}\left(Z_{4}-Z_{u s r R}\right)+c_{f L} \times \\
\left.\left(\dot{Z}_{2}-\dot{Z}_{u s f L}\right)+c_{r L}\left(\dot{Z}_{3}-\dot{Z}_{u s r L}\right)\right]+h_{R C f} \times \\
\left(F_{y f R} \cos \delta_{f R}+F_{x f R} \sin \delta_{f R}+F_{y f L} \cos \delta_{f L}+\right. \\
\left.F_{x f L} \sin \delta_{f L}\right)+h_{R C r}\left(F_{y r R}+F_{y r L}\right)+ \\
m_{s} g h_{s} \sin \theta \\
l_{f}\left[k_{f R}\left(Z_{1}-Z_{u s f R}\right)+k_{f L}\left(Z_{2}-Z_{u s f L}\right)\right]- \\
l_{r}\left[k_{r R}\left(Z_{4}-Z_{u s r R}\right)+k_{r L}\left(Z_{3}-Z_{u s r L}\right)\right]+ \\
l_{f}\left[c_{f R}\left(\dot{Z}_{2}-\dot{Z}_{u s f L}\right)+c_{f L}\left(\dot{Z}_{2}-\dot{Z}_{u s L}\right)\right]- \\
l_{r}\left[c_{r R}\left(\dot{Z}_{4}-\dot{Z}_{u s r R}\right)+c_{r L}\left(\dot{Z}_{3}-\dot{Z}_{u s r L}\right)\right]- \\
m_{s} g l_{s} \cos \phi+h_{R A}\left(F_{x f R} \cos \delta_{f r}-\right. \\
F_{y f R} \sin \delta_{f R}+F_{x f L} \cos \delta_{f L}-F_{y f L} \sin \delta_{f L}+ \\
\left.F_{x r R}+F_{x r L}\right) \\
\frac{t}{2}\left(-F_{x f R} \cos \delta_{f R}+F_{y f R} \sin \delta_{f R}+\right. \\
\left.F_{x f L} \cos \delta_{f L}-F_{y f L} \sin \delta_{f L}-F_{x r R}+F_{x r L}\right)- \\
l_{f}\left(F_{y f R} \cos \delta_{f R}+F_{x f R} \sin \delta_{f R}+F_{y f L} \sin \delta_{f L}\right. \\
\left.+F_{x f L} \sin \delta_{f L}\right)+l_{r}\left(F_{y r R}+F_{y r L}\right)
\end{array}\right\}
$$

In Equations (28) and (29) $Z_{n}$ is the displacement of a point of the sprung mass in the vertical direction above the unsprung masses, which is calculated according to Equation (30):

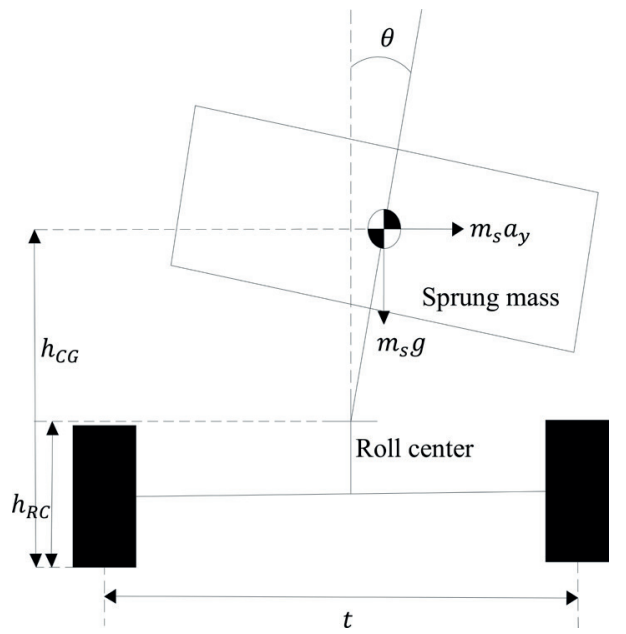

Figure 3 Vehicle's roll dynamics with stationary roll center 


$$
\begin{aligned}
& Z_{1}=Z_{C G S}+\frac{t}{2} \sin \theta-l_{f} \sin \phi, \\
& Z_{2}=Z_{C G S}-\frac{t}{2} \sin \theta-l_{f} \sin \phi, \\
& Z_{3}=Z_{C G S}-\frac{t}{2} \sin \theta+l_{r} \sin \phi, \\
& Z_{4}=Z_{C G S}+\frac{t}{2} \sin \theta+l_{r} \sin \phi .
\end{aligned}
$$

\subsection{Equations of engine rotating}

Generally, in deriving equations of a vehicle, the sprung mass is considered as rigid. Now, if a part of the sprung mass has a rotation, relative to the vehicle coordinate system (such as the engine crankshaft), then it is necessary to enter the effect of that rotation in the force-torque equations that have been calculated so far. In this study, it is assumed that the rotating components are symmetric, so the product of inertia multiplications is zero. In this case, the rotation of these components will not create any force and therefore the force equation remains stable. However, if the rotational velocity of the rotating components or their moment of inertia are significant, then the gyroscopic moments, due to the angular momentum of the rotating component, are considerable and their effect must be considered in the torque equation. The gyroscopic moment is obtained according to:

$\sum M=\left(\frac{d H}{d t}\right)_{S}+\omega_{s}^{V} \times H, H=I_{e}^{V} \omega_{e}^{V}$.

In Equation (31) $H$ is the angular momentum vector of the engine and the vector of the angular velocity of the engine in the vehicle coordinate system $\left(\omega_{e}^{V}\right)$ is considered according to:

$$
\omega_{e}^{V}=\left\{\dot{\theta} \dot{\phi} \cos \theta+\omega_{e} \dot{\varphi}+\dot{\phi} \sin \theta\right\}^{T} .
$$

In this study, the crankshaft coordinate axes are considered to correspond to the vehicle coordinate axes, in which case the product of the crankshaft inertia multiplications in the vehicle coordinates is also equal to zero. Thus:

$$
I_{e}^{V}=\left[\begin{array}{ccc}
I_{e} & 0 & 0 \\
0 & I_{a e} & 0 \\
0 & 0 & I_{e}
\end{array}\right]
$$

By placing Equations (32) and (33) in Equation (31), the gyroscopic moment vector in the vehicle coordinate system is obtained as:

$$
M_{V e}^{V}=\left\{\begin{array}{c}
I_{e}\left(\ddot{\theta}+\dot{\phi}^{2} \cos \theta \sin \theta+\dot{\varphi} \dot{\phi} \cos \theta\right)- \\
I_{a e}\left(\dot{\phi} \cos \theta+\omega_{e}\right)(\dot{\phi} \sin \theta+\dot{\varphi}) \\
I_{a e}\left(\ddot{\phi} \cos \theta-\dot{\theta} \dot{\phi} \sin \theta+\dot{\omega}_{e}\right) \\
I_{e}(\ddot{\varphi}+\ddot{\phi} \sin \theta)+I_{a e} \dot{\theta}\left(\dot{\phi} \cos \theta+\omega_{e}\right)
\end{array}\right\} .
$$

In Equation (34), $\omega_{e}$ is the angular velocity of the engine and $I_{a e}$ is the crankshaft inertia moment around its rotation axis. In this study, the gyroscopic moment of the crankshaft is considered like other external torques and is added directly to the torque vector of external forces.

\subsection{Wheels equations of motion}

The wheel's equations of motion in the vertical direction are determined according to Equations (35)(38). With writing the resultant of forces for each of the unsprung masses (Figure 4), one obtains:

$$
\begin{aligned}
& \sum_{\dot{Z}_{u s f R}} F_{z}+m_{u s i j} \ddot{Z}_{u s i j} \rightarrow k_{f R}\left(Z_{1}-Z_{u s f R}\right)+c_{f R}\left(\dot{Z}_{1}-\right. \\
& \left.\dot{Z}_{g f R}\right)=m_{u s f} \ddot{Z}_{u s f R}, \\
& k_{f L}\left(Z_{2}-Z_{u s f L}\right)+c_{t f}\left(\dot{Z}_{u s f R}\left(\dot{Z}_{2}-\dot{Z}_{u s f L}\right)+m_{u s f} g-\right. \\
& k_{t f}\left(Z_{u s f L}-Z_{g f L}\right)-c_{t f}\left(\dot{Z}_{u s f L}-\dot{Z}_{g f L}\right)=m_{u s f} \ddot{Z}_{u s f L}, \\
& k_{r L}\left(Z_{3}-Z_{u s r L}\right)+c_{r L}\left(\dot{Z}_{3}-\dot{Z}_{u s r L}\right)+m_{u s r} g- \\
& k_{t r}\left(Z_{u s r L}-Z_{g r L}\right)-c_{t r}\left(\dot{Z}_{u s r L}-\dot{Z}_{g r L}\right)=m_{u s r} \ddot{Z}_{u s r L}, \\
& k_{r R}\left(Z 4-Z_{u s r R}\right)+c_{r R}\left(\dot{Z}_{4}-\dot{Z}_{u s r R}\right)+m_{u s r} g- \\
& k_{t r}\left(Z_{u s r R}-Z_{g r R}\right)-c_{t r}\left(\dot{Z}_{u s r R}-\dot{Z}_{g r R}\right)=m_{u s r} \ddot{Z}_{u s r R} .
\end{aligned}
$$

\subsection{The tire modeling}

In this research, the model of Pacejka 89 (Magic Formula), which has the ability to estimate the lateral and longitudinal forces of the tire under the lateral and longitudinal slips, is considered [17-19]. This model receives variables such as vertical force of the wheel and longitudinal and lateral slips as input, while its output are the longitudinal and lateral forces of a tire. The longitudinal slip is considered based on Equations (39) and (40):

The longitudinal slip during the acceleration is:

$\alpha_{x}>0 \rightarrow \sigma=1-\left(V_{x} / V_{w}\right)$.

while the longitudinal slip during the braking is:

$a_{x}<0 \rightarrow \sigma=\left(V_{w} / V_{x}\right)-1$.

In Equations (39) and (40), $V_{w}=r_{w} \omega_{w}$ and the lateral slip angle is the difference between the direction of tire longitudinal axis and the direction of tire velocity vector in the xy plane (Figure 5). The lateral slip angles are obtained in the form:

$$
\begin{aligned}
& \alpha_{f R}=\arctan \left[\left(V_{y}+\dot{\varphi} l_{f}\right) /\left(V_{x}+\dot{\varphi} \frac{t}{2}\right)\right]-\delta_{f}, \\
& \alpha_{f L}=\arctan \left[\left(V_{y}+\dot{\varphi} l_{f}\right) /\left(V_{x}+\dot{\varphi} \frac{t}{2}\right)\right]-\delta_{f},
\end{aligned}
$$




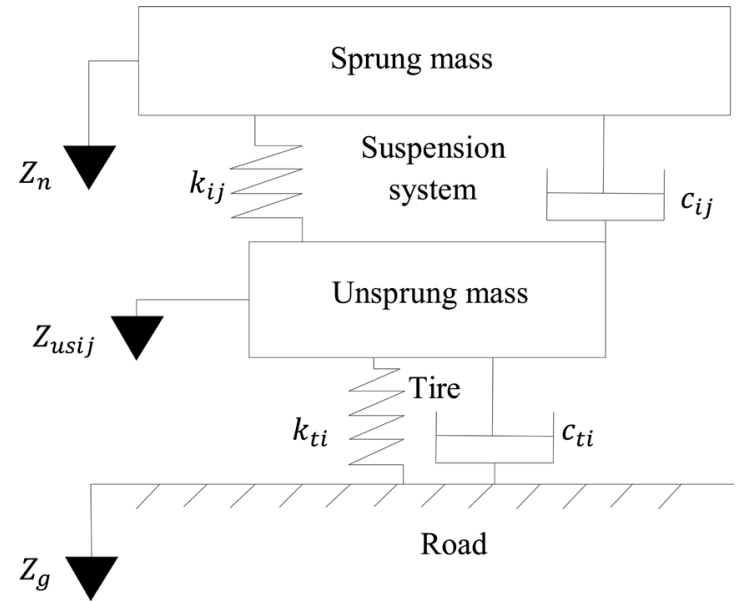

Figure 4 Modeling of the unsprung mass

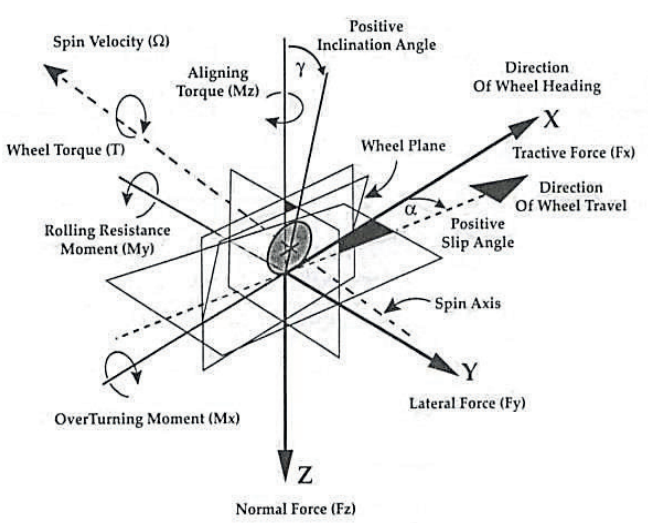

Figure 5 Tire coordinates according to the $S A E$ standard [17]

$$
\begin{aligned}
& \alpha_{f R}=\arctan \left[\left(V_{y}+\dot{\varphi} l_{r}\right) /\left(V_{x}+\dot{\varphi} \frac{t}{2}\right)\right], \\
& \alpha_{f L}=\arctan \left[\left(V_{y}+\dot{\varphi} l_{r}\right) /\left(V_{x}+\dot{\varphi} \frac{t}{2}\right)\right] .
\end{aligned}
$$

Therefore, the longitudinal and lateral forces of the tire are obtained according to Equations (43) and (44) by determining the longitudinal slip and lateral slip angle. In the appendix 1 , the constants of the Magic Formula (Pacejka 89) are given and longitudinal and lateral forces of the Magic Formula are shown in Figures 6 and 7.

$$
\begin{aligned}
& F_{x}=D \sin \left(C \operatorname { a r c t a n } \left(B X_{1}-E\left(B X_{1}-\right.\right.\right. \\
& \left.\left.\left.\arctan \left(B X_{1}\right)\right)\right)\right)+S v, C=b_{0}, D=\left(b_{1} F_{z}^{2}+b_{2} F_{z}\right), \\
& B C D=\left(b_{3} F_{z}^{2}+b_{4} F_{z}\right) e^{\left(-b_{5} F_{z}\right)}, B=B C D(C / D), \\
& E=\left(b_{6} F_{z}^{2}+b_{7} F_{z}+b_{8}\right), S h=b_{9} F_{z}+b_{10}, \\
& S v=0, X_{1}=\sigma+S h, \\
& F_{y}=D \sin \left(C \operatorname { a r c t a n } \left(B X_{1}-E\left(B X_{1}-\right.\right.\right. \\
& \left.\left.\left.\arctan \left(B X_{1}\right)\right)\right)\right)+S v, C=a_{0}, D=\left(a_{1} F_{z}^{2}+a_{2} F_{z}\right), \\
& B C D=a_{3} \sin \left(\arctan \left(F_{z} / a_{4}\right)\right)\left(1-a_{5}|\gamma|\right), \\
& B=B C D(C / D), E=\left(a_{6} F_{z}+a_{7}\right), \\
& S h=a_{9} F_{z}+a_{10}+a_{8} \gamma, \\
& S v=a_{11} F_{z} \gamma+a_{12} F_{z}+a_{13}, X_{1}=\sigma+S h .
\end{aligned}
$$

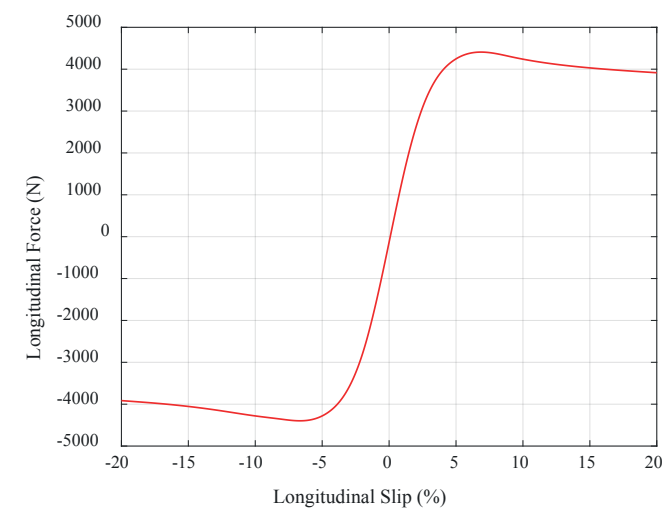

Figure 6 Variation of the longitudinal force of the Magic Formula according to longitudinal slip

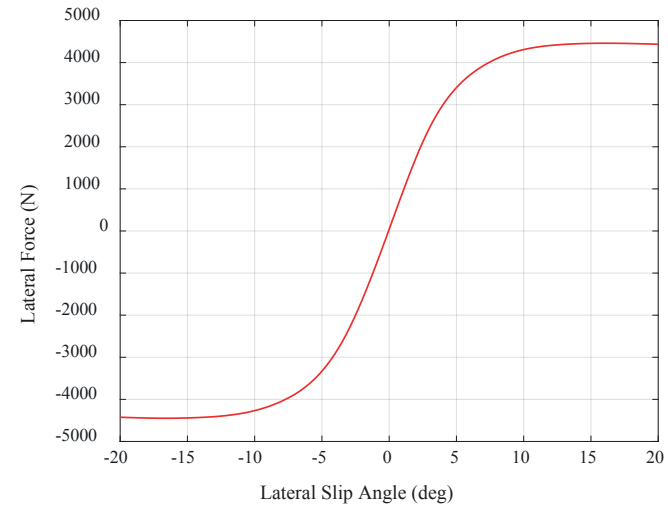

Figure 7 Variation of the lateral force of the Magic Formula according to lateral slip angle

\section{$3 \quad$ Numerical method}

By using the Newmark numerical method in the form of time integration [25], vehicle's dynamic behavior is simulated. In the Newmark methods family, at time of $\tau$ the vector of displacement $(q)$, velocity $(\dot{q})$ and acceleration $(\ddot{q})$ are estimated by $E_{d+1}, \dot{E}_{d+1}$ and $a_{d+1}$ at time of $\tau_{d+1}$. The vehicle's displacement vector is selected as Equation (45) and the governing matrixvector equations at time $\mathrm{f} \tau=\tau_{d+1}$ can be changed to an estimated prescription as Equation (46).

$q=\left\{X, Y, Z_{C G S}, \theta, \varphi, \phi, Z_{u s f R}, Z_{u s j L}, Z_{u s r R}, Z_{u s r L}\right\}^{T}$,

$\Gamma\left(E_{d+1}\right) a_{d+1}+G\left(E_{d+1}, \dot{E}_{d+1}\right)=\Lambda_{d+1}$

$E_{0}=E(0), \dot{E}_{0}=\dot{E}(0)$,

$a_{0}=-\Gamma^{-1}(E(0)) G(E(0), \dot{E}(0))$.

where, $\Gamma$ is the inertia matrix and $\Gamma$ and $G$ are functions of the displacement and velocity, $\Lambda$ is the vector of external excitations, $E_{0}$ is the initial displacement, $\dot{E}_{0}$ is the initial velocity and $a_{0}$ is the initial acceleration. Displacement and velocity can be predicted by: 
$\hat{E}_{d}=E_{d}+\Delta \tau \dot{E}_{d}+0.5 \Delta \tau^{2}(1-2 \xi) a_{d}$,

$\hat{\dot{E}}_{d}=\dot{E}_{d}+(1-\eta) \Delta \tau a_{d}$.

respectively, where $\Delta \tau=\tau_{d+1}-\tau_{d}$ is the time step size, $\xi$ and $\eta$ are the Newmark's algorithm parameters which show the accuracy of the algorithmic. Updated displacement and velocity are obtained from Equations (49) and (50), respectively:

$$
\begin{aligned}
& E_{d+1}=\hat{E}_{d}+\xi \Delta \tau^{2} a_{d+1}, \\
& \dot{E}_{d+1}=\hat{\dot{E}}_{d}+\eta \Delta \tau a_{d+1} .
\end{aligned}
$$

In order to obtain $E_{d+1}$ and $\dot{E}_{d+1}$, an update of the acceleration must be known $\left(a_{d+1}\right)$. By using method the Newton-Raphson for each time step and by placing Equations (49) and (50) into Equation (46), $a_{d+1}$ is obtained from:

$$
\begin{aligned}
& \Delta a_{d+1}^{u}+a_{d+1}^{u}=a_{d+1}^{u+1}, \\
& J_{d+1}^{u} \Delta a_{d+1}^{u}=-\Gamma_{d+1}^{u} a_{d+1}^{u}-G_{d+1}^{u}+\Lambda_{d+1},
\end{aligned}
$$

where, $d$ and $u$ are the iteration number of the time step and Newton-Raphson method, $\Gamma_{d+1}^{u}=\Gamma\left(E_{d+1}^{u}\right)$, $G_{d+1}^{u}=G\left(E_{d+1}^{u}, \dot{E}_{d+1}^{u}\right)$ and $J_{d+1}^{u}$ is the Jacobian matrix and is defined as:

$$
\begin{aligned}
& J_{d+1}^{u}=\Gamma\left(E_{d+1}^{u}\right)+\xi \Delta \tau^{2}\left[\frac{\partial J_{d+1}^{u} a_{d+1}^{u}}{\partial E_{d+1}^{u}}+\frac{\partial G_{d+1}^{u}}{\partial E_{d+1}^{u}}\right]+ \\
& \eta \Delta \tau \frac{\partial G_{d+1}^{u}}{\partial \dot{E}_{d+1}^{u}} .
\end{aligned}
$$

The process of the Newmark method is shown in Figure 8.

\section{Validation and simulation results}

Several different test programs in the phase IV of the light vehicle rollover research program were reviewed and evaluated to select the most appropriate maneuver to investigate the rollover. According to Table 1, it can be seen that one of the best maneuvers is the J-turn test, which has obtained the highest score. Due to the fact that the vehicle is assumed to be perfectly symmetrical with respect to its $x z$ plane, direction of the steering wheel angle (clockwise or counterclockwise) of Figure 9 has no effect on the maneuver results. The initial speed of the vehicle is shown in Figures 10 and 11 and the engine speed is 5000 rpms. During the J-turn maneuver, the passed trajectory by the vehicle is shown in Figure 12. By applying the steering wheel angle according to Figure 9 , the Newmark numerical method and parameters of Table 2, the dynamic behavior of the vehicle is compared by ADAMS/Car software according to Figures 13 and 14. Based on the validation results, it is found that the 15 -DOF presented model in this research simulates the vehicle's dynamic behavior with a good accuracy. According to the numerical results (Figures 13b, 14b, 15 and 16), by applying the steering input, the lateral acceleration reaches about $-0.8 \mathrm{~g}$ and finally decreases with decreasing longitudinal velocity of a vehicle.

The maximum roll angle and roll rate of a vehicle reach about $8^{\circ}$ and $40 \%$. Moreover, the yow rate of the vehicle reaches a maximum of about $-41 \% \mathrm{~s}$ and then decreases to about $-15 \% / \mathrm{s}$ and finally reaches about $-35 \%$ s.

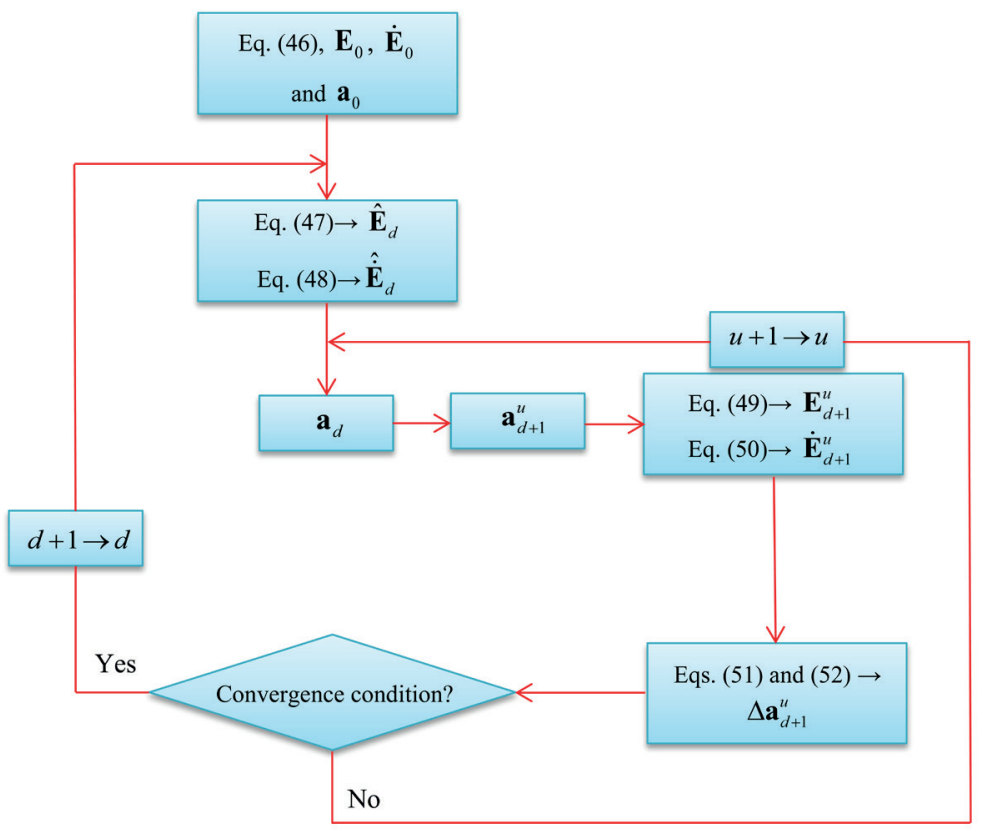

Figure 8 Flowchart of the Newmark numerical method 

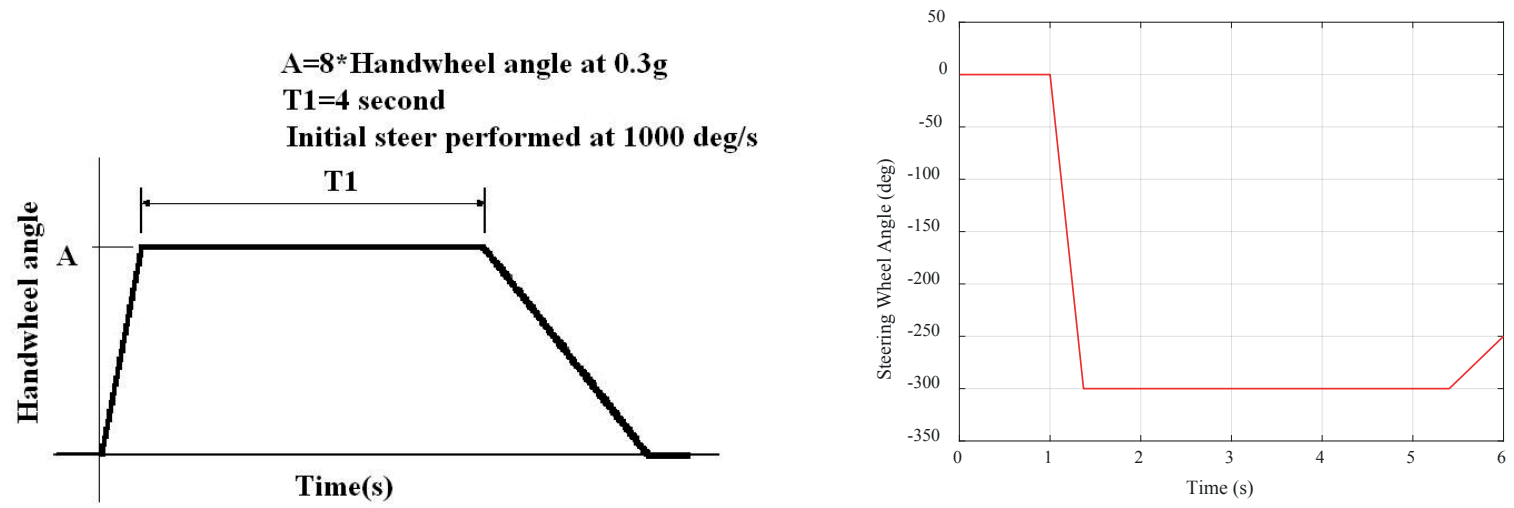

(a)

(b)

Figure 9 Schematics of the steering wheel angle of a vehicle in:

(a) NHTSA J-turn maneuver [2] and (b) this study

Table 1 Comparison of different rollover maneuvers [2]

\begin{tabular}{ccccc}
\hline assessment criterion & NHTSA J-turn & fishhook \#1a & fishhook \#1b & Nissan fishhook \\
\hline objectivity and repeatability & excellent & excellent & excellent & good \\
performability & excellent & good & excellent & satisfactory \\
discriminatory capability & excellent & excellent & excellent & excellent \\
appearance of reality & good & excellent & excellent & good \\
\hline
\end{tabular}

Table 2 System parameters of this study

\begin{tabular}{|c|c|c|c|c|c|}
\hline parameter & value & unit & parameter & value & unit \\
\hline$m_{s}$ & 808 & $\mathrm{Kg}$ & $c_{r}$ & 882.9 & N.s/m \\
\hline$m_{u s f}$ & $2 \times 31.5$ & $\mathrm{Kg}$ & $I_{x}$ & 298 & $\mathrm{Kg} \cdot \mathrm{m}^{2}$ \\
\hline$m_{u s r}$ & $2 \times 29.5$ & $\mathrm{Kg}$ & $I_{y}$ & 1243 & $\mathrm{Kg} \cdot \mathrm{m}^{2}$ \\
\hline$h_{C G}$ & 0.54 & $\mathrm{~m}$ & $I_{z}$ & 1130 & $\mathrm{Kg} \cdot \mathrm{m}^{2}$ \\
\hline$h_{R A}$ & 0.1 & $\mathrm{~m}$ & $r_{w}$ & 0.257 & $\mathrm{~m}$ \\
\hline$t$ & 1.4 & $\mathrm{~m}$ & $h_{R C}$ & 0.1 & $\mathrm{~m}$ \\
\hline$l_{f}$ & 0.945 & $\mathrm{~m}$ & $h_{s}$ & 0.45 & $\mathrm{~m}$ \\
\hline$l_{r}$ & 1.4 & $\mathrm{~m}$ & $I_{a e}$ & 1.5 & Kg. $\mathrm{m}^{2}$ \\
\hline$k_{f}$ & 16 & $\mathrm{kN} / \mathrm{m}$ & $k_{t f}$ & 160 & $\mathrm{kN} / \mathrm{m}$ \\
\hline$k_{r}$ & 15.4 & $\mathrm{kN} / \mathrm{m}$ & $k_{t r}$ & 154 & $\mathrm{kN} / \mathrm{m}$ \\
\hline$c_{f}$ & 1414.3 & N.s/m & $\xi$ & 0.25 & - \\
\hline$c_{t}$ & 0 & N.s $/ \mathrm{m}$ & $\eta$ & 0.5 & - \\
\hline$l_{s}$ & 0.35 & $\mathrm{~m}$ & & & \\
\hline
\end{tabular}

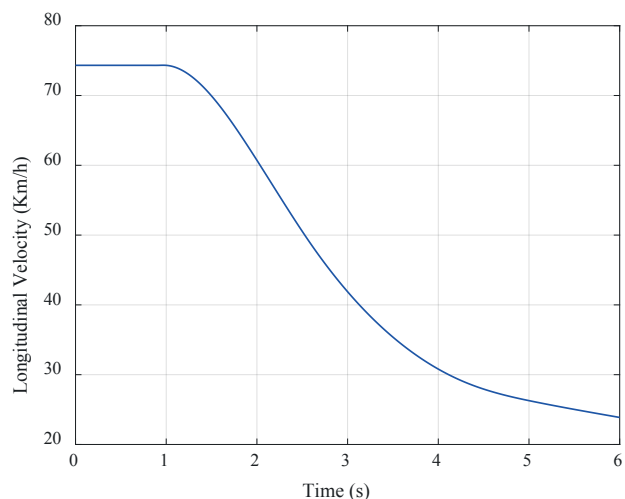

Figure 10 The longitudinal velocity of the vehicle in the J-turn maneuver

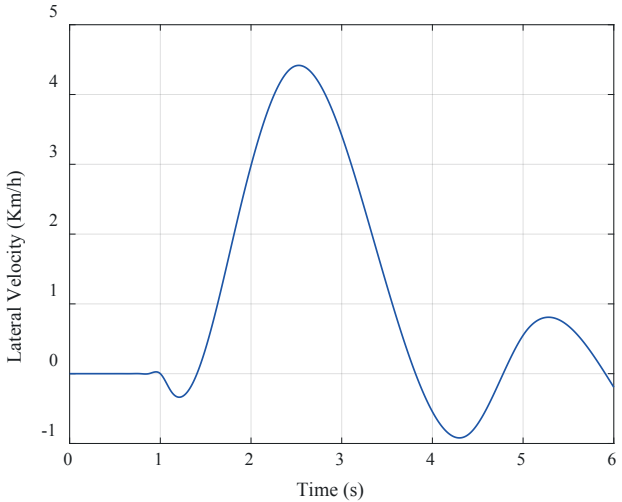

Figure 11 The lateral velocity of the vehicle in the J-turn maneuver 


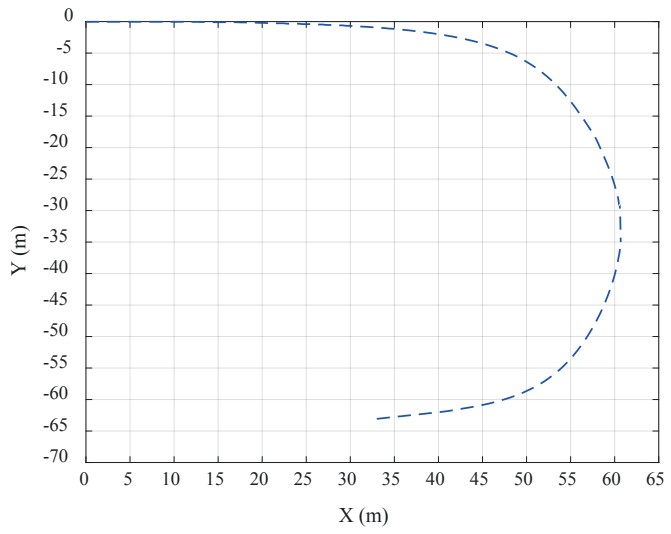

Figure 12 Trajectory of a vehicle in the J-turn maneuver

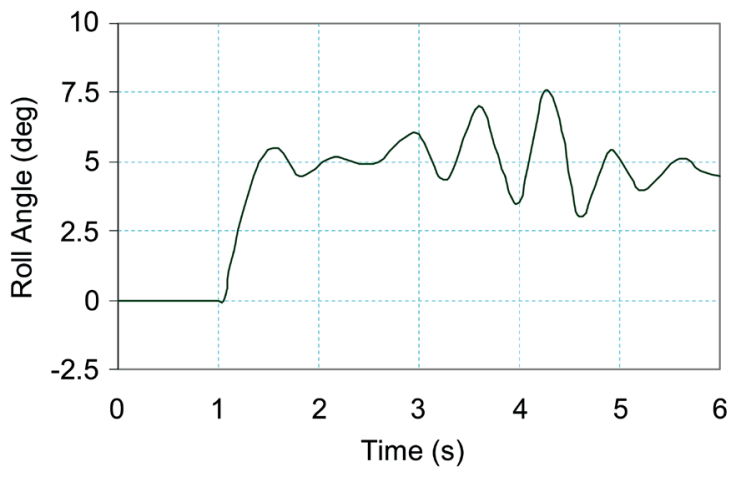

(a)

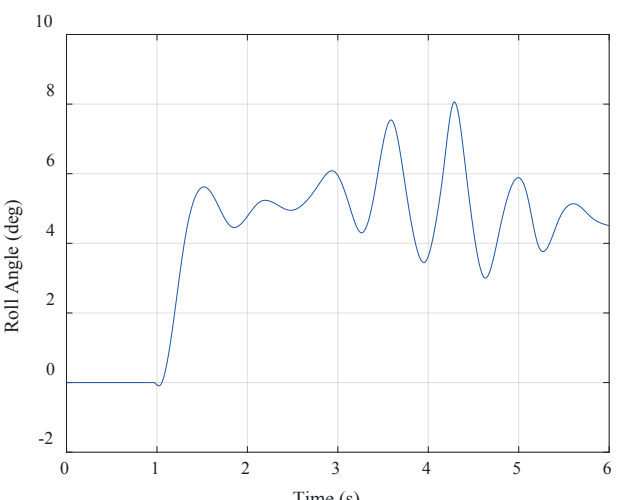

(b)

Figure 13 The roll angle of the vehicle in the J-turn maneuver: (a) ADAMS software and (b) this study

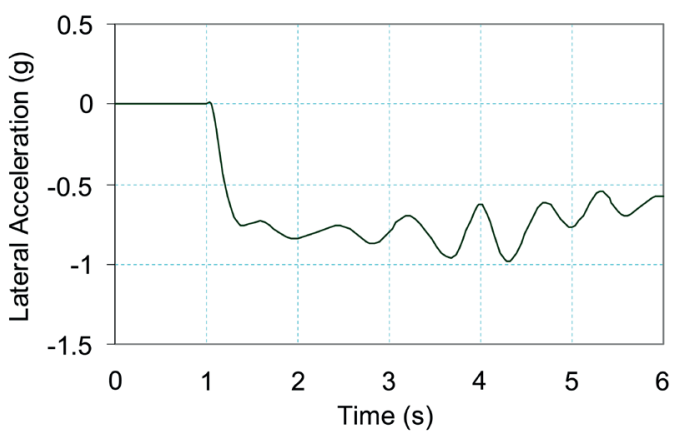

(a)

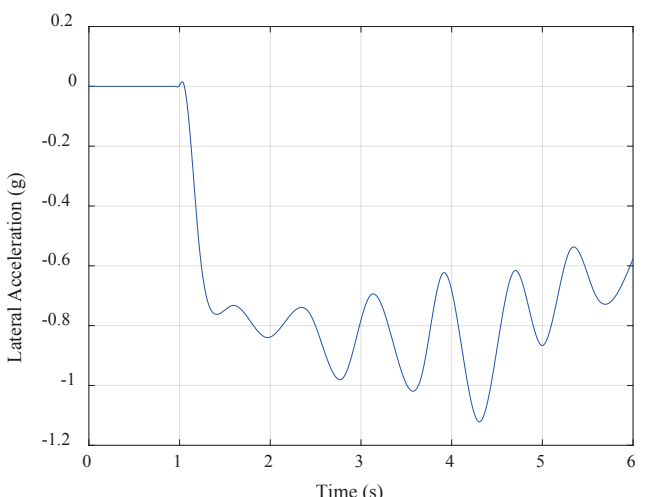

(b)

Figure 14 The lateral acceleration of the vehicle in the J-turn maneuver: (a) ADAMS software and (b) this study

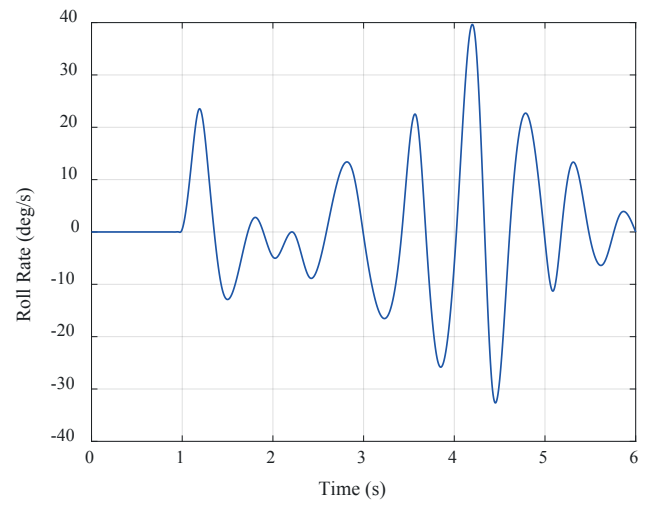

Figure 15 The roll rate of the vehicle in the J-turn maneuver

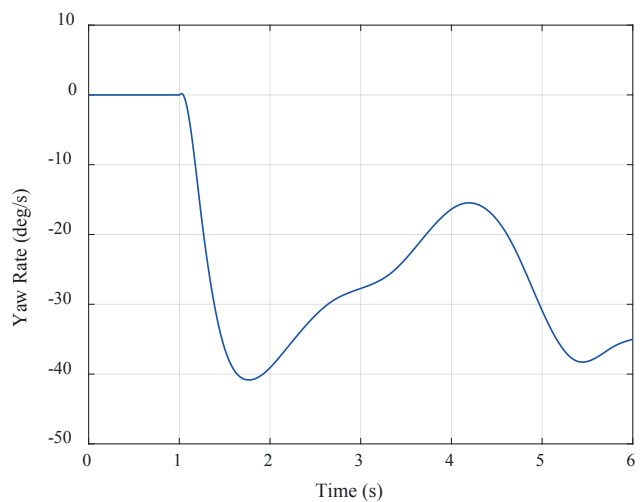

Figure 16 The yaw rate of the vehicle in the J-turn maneuver 


\section{Conclusions}

This study presents the dynamics of a 15-DOF model of a vehicle by performing simulations to investigate the vehicle's dynamic behavior in the J-turn maneuver under the supervision of the phase IV of NHTSA's light vehicle rollover research program. Using the Newton's equations of motion, the equations of motion for the sprung and unsprung masses are all written in the vehicle coordinate system. In order to study the engine dynamics, the crankshaft coordinate axes are considered to correspond to the vehicle coordinate axes. Finally, the gyroscopic moment of the crankshaft is added directly to the torque vector of external forces and the governing equations are evaluated by numerical method of the Newmark. The tire is modeled with the Pacejka 89 model, which estimates the tire forces by using the longitudinal and lateral slips. By selecting the J-turn maneuver, the dynamic behavior of the presented $15-\mathrm{DOF}$ model is validated by ADAMS/Car software. Based on the simulation results, it is found that the 15-DOF model, presented in this research, simulates the vehicle's dynamic behavior with a good accuracy. By applying the steering input the lateral acceleration reaches about $-0.8 \mathrm{~g}$ and finally decreases with decreasing longitudinal velocity of the vehicle. The maximum roll angle and roll rate of the vehicle reach about $8^{\circ}$ and $40 \%$. The yaw rate of a vehicle reaches a maximum of about $-41 \% \mathrm{~s}$ and then decreases to about $-15 \% / \mathrm{s}$ and finally reaches about $-35 \%$ s.

\section{References}

[1] HEYDINGER, G. J., HOWE, J. G. Analysis of vehicle response data measured during severe maneuvers. SAE Technical Papers [online]. 2000, 01, 1644, p. 2154-2167. ISSN 0148-7191, eISSN 2688-3627. Available from: https://doi.org/10.4271/2000-01-1644

[2] FORKENBROCK, G. J., GARROTT, W. R., HEITZ, M., O'HARRA, B. C. A comprehensive experimental examination of test maneuvers that may induce on-road, untripped, light vehicle rollover [online]. Report DOT HS 809 513. Phase IV of NHTSA's Light Vehicle Rollover Research Program. NHTSA, 2002. Available from: https://moam.info/a-comprehensive-experimental-examination-of-test-maneuvers-_59b212851723ddddc6092afb. html

[3] COOPERRIDER, N. K., THOMAS, T. M., HAMMOUD, S. A. Testing and analysis of vehicle rollover behavior. SAE Technical Papers [online]. 1990, 900366, p. 518-527. ISSN 0148-7191, eISSN 2688-3627. Available from: https://doi.org/10.4271/900366

[4] LABUDA, R., KOVALCIK, A., REPKA, J., HLAVNA, V. Simulation of a wheeled vehicle dynamic regimes in laboratory conditions. Communications-Scientific Letters of the University of Zilina [online]. 2012, 14(3), p. 5-9. ISSN 1335-4205, eISSN 2585-7878. Available from: http://komunikacie.uniza.sk/index.php/communications/ article/view/753

[5] SINDHA, J., CHAKRABORTY, B., CHAKRAVARTY, D. System identification and lateral dynamics of the active tilt-controlled electric three wheeler. Journal of Dynamic Systems, Measurement and Control [online], 2020, 142(9), 091001. ISSN 0022-0434. Available from: https://doi.org/10.1115/1.4046798

[6] ZHANG, J., WANG, H., ZHENG, J., CAO, Z., MAN, Z., YU, M., CHEN, L. Adaptive sliding mode-based lateral stability control of steer-by-wire vehicles with experimental validations. IEEE Transactions on Vehicular Technology [online]. 2020, 69(9), p. 9589-9600. ISSN 0018-9545. Available from: https://doi.org/10.1109/ TVT.2020.3003326

[7] PHANOMCHOENG, G., RAJAMANI, R. New rollover index for the detection of tripped and untripped rollovers. IEEE Transactions on Industrial Electronics [online]. 2012, 60(10), p. 4726-4736. ISSN 0278-0046. Available from: https://doi.org/10.1109/TIE.2012.2211312

[8] CHEN, Y., ZHENG, X., PETERSON, A., AHMADIAN, M. Simulation evaluation on the rollover propensity of multi-trailer trucks at roundabouts. SAE Technical Papers [online]. 2020, 01, 5005. ISSN 0148-7191, eISSN 2688-3627. Available from: https://doi.org/10.4271/2020-01-5005

[9] LOKTEV, D. A., LOKTEV, A. A., SAlNiKOVA, A. V., SHAFOROSTOVA, A. A. Determination of the dynamic vehicle model parameters by means of computer vision. Communications-Scientific Letters of the University of Zilina [online]. 2019, 21(3), p. 28-34. ISSN 1335-4205, eISSN 2585-7878. Available from: https://doi.org/10.26552/com.C.2019.3.28-34

[10] PHALKE, T. P., MITRA, A. C. Analysis of ride comfort and road holding of quarter car model by SIMULINK. Materials Today: Proceedings [online]. 2017, 4(2), p. 2425-2430. ISSN 2214-7853. Available from: https://doi.org/10.1016/j.matpr.2017.02.093

[11] SAGA, M., LETRICH, M., KOCUR, R. An analysis of vehicle vibration with uncertain system parameters. Communications-Scientific Letters of the University of Zilina [online]. 2005, 7(1), p. 16-21. ISSN 1335-4205, eISSN 2585-7878. Available from: http://komunikacie.uniza.sk/index.php/communications/article/view/1223 
[12] KAZEMIAN, A. H., FOOLADI, M., DARIJANI, H. Rollover index for the diagnosis of tripped and untripped rollovers. Latin American Journal of Solids and Structures [online]. 2017, 14(11), p. 1979-1999. ISSN 1679-7817. Available from: https://doi.org/10.1590/1679-78253576

[13] KAZEMIAN, A. H., FOOLADI, M., DARIJANI, H. Non-linear control of vehicle's rollover using sliding mode controller for new 8 degrees of freedom suspension model. International Journal of Heavy Vehicle Systems [online]. 2019, 26(5), p. 707-726. ISSN 1744-232X. Available from: https://doi.org/10.1504/IJHVS.2019.101888

[14] RAJAMANI, R. Vehicle dynamics and control [online]. USA: Springer Science and Business Media, 2011. ISBN 978-1-4614-1432-2, eISBN 978-1-4614-1433-9. Available from: https://doi.org/10.1007/978-1-4614-1433-9

[15] GILLESPIE, T. D. Fundamentals of vehicle dynamics. 4. ed. Warrendale: Society of Automotive Engineers, 1992. ISBN 978-1-56091-199-9.

[16] MERIAM, J. L., KRAIGE, L. G. Engineering mechanics: dynamics. John Wiley and Sons, Inc., 2012. ISBN 9780470614815.

[17] PACEJKA, H. Tire and vehicle dynamics. 2. ed. Elsevier, 2005. ISBN 9780750669184, eISBN 9780080543338.

[18] BAKKER, E., PACEJKA, H. B., LIDNER, L. A new tire model with an application in vehicle dynamics studies. SAE Technical Papers [online]. 1989, 890087, p. 101-113. ISSN 0148-7191, eISSN 2688-3627. Available from: https://doi.org/10.4271/890087

[19] PACEJKA, H. B., BAKKER, E. The magic formula tire model. Vehicle System Dynamics [online]. 1992, 21(S1), p. 1-18. ISSN 0042-3114. Available from: https://doi.org/10.1080/00423119208969994

[20] BURIAKOVSKYI, S., LIUBARSKYI, B., MASLII, A., POMAZAN, D., TAVRINA, T. Research of a hybrid diesel locomotive power plant based on a free-piston engine. Communications-Scientific Letters of the University of Zilina [online]. 2020, 22(3), p. 103-109. ISSN 1335-4205, eISSN 2585-7878. Available from: https://doi.org/10.26552/com.C.2020.3.103-109

[21] ISKRA, A., BABIAK, M., KALUZNY, J. Identification of the combustion Engine resistance to motion torque components. Communications-Scientific Letters of the University of Zilina [online]. 2011, 13(4), p. 12-15. ISSN 1335-4205, eISSN 2585-7878. Available from: http://komunikacie.uniza.sk/index.php/communications/ article/view/871

[22] LAHMAR, M., FRIHI, D., NICOLAS, D. The effect of misalignment on performance characteristics of engine main crankshaft bearings. European Journal of Mechanics-A/Solids [online]. 2002, 21(4), p. 703-714. ISSN 0997-7538. Available from: https://doi.org/10.1016/S0997-7538(01)01202-5

[23] AHMADABADI, Z. N. Nonlinear energy transfer from an engine crankshaft to an essentially nonlinear attachment. Journal of Sound and Vibration [online]. 2019, 443, p. 139-154. ISSN 1095-8568. Available from: https://doi.org/10.1016/j.jsv.2018.11.040

[24] HUANG, T., ZHANG, J., CHEN, G, WANG, C. Dynamic balance two-dimensional measuring of crankshaft assembly in motorcycle engine. IEEE Access [online]. 2020, 8, p. 133757-133766. ISSN 2169-3536. Available from: https://doi.org/10.1109/ACCESS.2020.3010171

[25] NEWMARK, N. M. A method of computation for structural dynamics. Journal of the Engineering Mechanics Division [online]. 1959, 85(3), p. 67-94. ISSN 0044-7951, eISSN 2690-2427. Available from: https://cedb.asce.org/ CEDBsearch/record.jsp?dockey $=0011858$

[26] REZAEI, V., SHAFEI, A. M. Dynamic analysis of flexible robotic manipulators constructed of functionally graded materials. Iranian Journal of Science and Technology, Transactions of Mechanical Engineering [online]. 2019, 43(1), p. 327-342. ISSN 2228-6187. Available from: https://doi.org/10.1007/s40997-018-0160-2

[27] JANOT, A., WENSING, P. M. Sequential semidefinite optimization for physically and statistically consistent robot identification. Control Engineering Practice [online]. 2021, 107, p. 104699. ISSN 0967-0661. Available from: https://doi.org/10.1016/j.conengprac.2020.104699

[28] ZHANG, Y., LIU, H., MA, T., HAO, L., LI, Z. A comprehensive dynamic model for pneumatic artificial muscles considering different input frequencies and mechanical loads. Mechanical Systems and Signal Processing [online]. 2021, 148, p. 107133. ISSN 0888-3270. Available from: https://doi.org/10.1016/j.ymssp.2020.107133

\section{Appendix 1}

The transformation relation between the coordinate systems of the sprung mass and a vehicle, which results from the pitch and roll rotation, is obtained as follows:

$R_{S}^{V}=\left[\begin{array}{ccc}\cos \phi & 0 & \sin \phi \\ 0 & 1 & 0 \\ -\sin \phi & 0 & \cos \phi\end{array}\right]\left[\begin{array}{ccc}1 & 0 & 1 \\ 0 & \cos \theta & -\sin \theta \\ 1 & \sin \theta & \cos \theta\end{array}\right]=\left[\begin{array}{ccc}\cos \phi & \sin \phi \sin \theta & \sin \phi \cos \theta \\ 0 & \cos \theta & -\sin \theta \\ -\sin \phi & \cos \phi \sin \theta & \cos \phi \cos \theta\end{array}\right]$ 
Table A.1 Constant values used in the Pacejka 89 tire model

\begin{tabular}{cc}
\hline lateral constants & longitudinal constants \\
\hline$a_{0}=1.65, a_{1}=-34, a_{2}=1250$, & $b_{0}=2.37272, b_{1}=-9.46, b_{2}=1490$, \\
$a_{3}=3036, a_{4}=12.8, a_{5}=0.00501$, & $b_{3}=130, b_{4}=276, b_{5}=0.0886$, \\
$a_{6}=-0.02103, a_{7}=0.77394$, & $b_{6}=0.00402, b_{7}=-0.0615, b_{8}=1.2$, \\
$a_{8}=0.002289, a_{9}=0.013442$, & \\
$a_{10}=0.003709, a_{11}=19.1656$, & \\
$a_{12}=1.21356, a_{13}=6.26206$ & \\
\hline
\end{tabular}

\section{Appendix 2}

\begin{tabular}{|c|c|}
\hline nomenclature & meaning \\
\hline$a$ & acceleration and lateral constants of the Magic Formula \\
\hline$b$ & longitudinal constants of the Magic Formula \\
\hline$c$ & damping coefficient \\
\hline$F$ & force \\
\hline$h$ & height \\
\hline$H$ & angular momentum \\
\hline$I$ & moment of inertia \\
\hline$k$ & stiffness coefficient \\
\hline$m$ & mass \\
\hline$M$ & torque \\
\hline$r$ & radius \\
\hline$R$ & function of coordinate transformation \\
\hline$t$ & track width \\
\hline$V$ & velocity \\
\hline$Z$ & vertical displacement \\
\hline$\alpha$ & lateral slip angle \\
\hline$\gamma$ & camber angle \\
\hline$\delta$ & steering input \\
\hline$\theta$ & roll angle \\
\hline$\sigma$ & longitudinal slip \\
\hline$\varphi$ & yaw angle \\
\hline$\phi$ & pitch angle \\
\hline$\omega$ & angular velocity \\
\hline subscripts & meaning \\
\hline$a e$ & crankshaft \\
\hline$C G$ & center of gravity \\
\hline$e$ & engine \\
\hline$f$ & front \\
\hline$g$ & road \\
\hline$i$ & front and rear wheels $(f, r)$ \\
\hline$j$ & right and left wheels $(L, R)$ \\
\hline$L$ & left side \\
\hline$r$ & rear \\
\hline$R$ & right side \\
\hline$R A$ & roll axis \\
\hline$R C$ & roll center \\
\hline$s$ & sprung mass \\
\hline$t$ & tire \\
\hline us & unsprung mass \\
\hline$V$ & vehicle \\
\hline$w$ & wheel \\
\hline$x$ & longitudinal direction \\
\hline$y$ & lateral direction \\
\hline$z$ & vertical direction \\
\hline
\end{tabular}


Project

\section{Creation of a Digital Biobank to Support the Systemic Public Research Infrastructure is co-financed by the European Union}

\section{Project objective:}

Expansion and completion of research and innovation infrastructure and capacities for the development of excellence in research and innovation through the establishment of a data biobanking system and its integration into the international network of research infrastructures.

\section{Project description:}

The project is focused on the so-called digital banking of medical data that will be related to a specific sample of biological material. These are data from hospital information systems - clinical anonymized data, data from the laboratory information management system, data from the research information system and data from the PACS. The obtained data will be analysed bioinformatically, biostatistically and artificial intelligence algorithms can be applied to them. The digital biobank will also support the possibility of creating so-called digital pathology, which is a unique issue in the Slovak environment.

\section{Beneficiary: University of Žilina}

\section{In cooperation with:}

Ministry of Health of the Slovak Republic

Comenius University in Bratislava

\section{Contracted amount of the Non-Repayable Financial Contribution:}

11590338,03 EUR

Project duration: 06/2020 - 06/2023

ITMS2014+ code: 313011AFG4

This publication has been produced with the support of the Integrated Infrastructure Operational Program for the project: Creation of a Digital Biobank to Support the Systemic Public Research Infrastructure, ITMS: 313011AFG4, co-financed by the European Regional Development Fund.

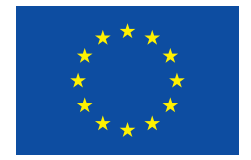

